\title{
Assessering van die onkruidspektrum en assosiasies daarvan met onderdrukkende verbouingstrategieë op George
}

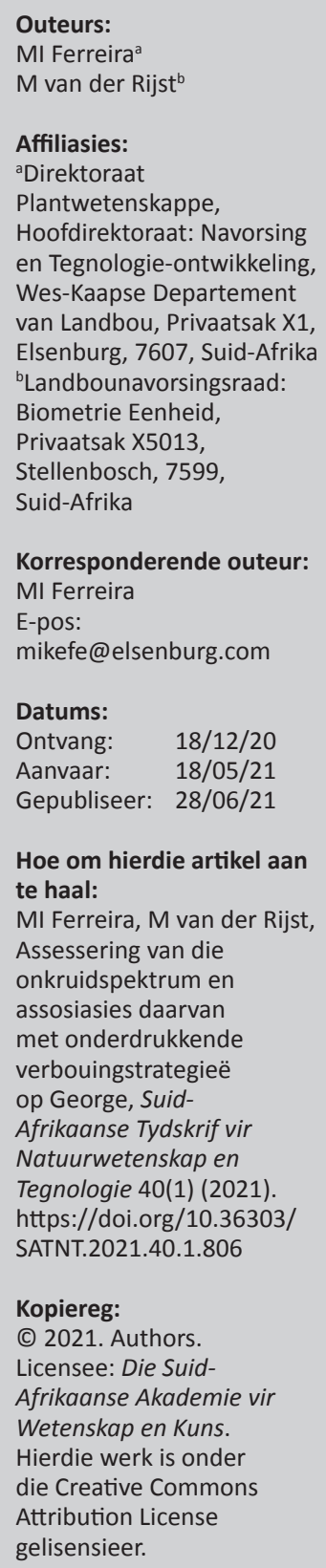

Hoe om hierdie artikel aan te haal:

MI Ferreira, M van der Rijst, Assessering van die onkruidspektrum en assosiasies daarvan met onderdrukkende verbouingstrategieë op George, SuidAfrikaanse Tydskrif vir Natuurwetenskap en Tegnologie 40(1) (2021). https://doi.org/10.36303/ SATNT.2021.40.1.806

Kopiereg:

(C) 2021. Authors. Licensee: Die SuidAfrikaanse Akademie vir Wetenskap en Kuns. Hierdie werk is onder die Creative Commons Attribution License gelisensieer.

\begin{abstract}
Onkruide is een van die grootste produksie-knelpunte in gewasverbouing en kan oesopbrengs op grond van spesiesamestelling en digtheid beïnloed. ' $n$ Veldproef is van stapel gestuur om die samestelling van die onkruidspektrum te beoordeel en omgewingsvriendelike praktyke wat onkruide onderdruk, te evalueer. Die hoofdoel van hierdie studie was, eerstens, om die spesies-samestelling van die onkruidspektrum te bepaal sodat die bestaande oorvloedigheidsindeks bereken kon word, en tweedens, om assosiasies van die onkruidspektrum na behandeling met onderdrukkende verbouingstrategieë te bepaal. Onkruide is by elke bemonsteringspunt geïdentifiseer en die aantal individuele plante afsonderlik aangeteken. Hoofkomponent Analise is gebruik om aan te toon hoe behandelings in verband staan tot die onkruidspektrum. Onkruidspesies behorende aan 19 plantfamilies, is geïdentifiseer. Wintergras (Poa annua) was die volopste winteronkruid met 'n indekswaarde van 34.9. Geeluintjies (Cyperus esculentus) was die volopste someronkruid met 'n indekswaarde van 74.8. As someronkruid het knopkruid (Galinsoga parviflora) sterk assosiasies met sommige behandelings getoon. Verskeie behandelings het doeltreffende onderdrukking tot gevolg gehad waarmee geen winteronkruide assosiasies kon vorm nie. Hardnekkige en skadelike onkruidspesies kan deur nie-chemiese strategieë bestuur word deur die integrering van geen-bewerking, verbouing van smoorgewasse met 'n peulgewaskomponent, platsny van gewasse, en laasgenoemde op te volg deur fynkap van biomassa met 'n deklaagimplement. In die konteks van plaaslike toestande kan dit meer wenslike (lae kompeterende) onkruidspesies bevorder wat sodoende skadelike (hoog kompeterende) onkruidsoorte onderdruk.
\end{abstract}

Sleutelwoorde: bossiekap, deklaagbewerking, deklaagimplement, geen-bewerking, onkruidonderdrukking

Assessment of the weed spectrum and its associations with suppressive cultivation strategies on George: Weeds are one of the major constraints to crop cultivation that can affect crop yield based on their species composition and density. A field trial was initiated to assess the weed community composition and evaluate eco-friendly weed suppressive strategies. The main objective of this study was first to assess the floristic composition to determine pre-existing weed abundance and secondly to determine the response in terms of relative weed density subsequent to treatments. The identification of weeds occurred at each sampling point and the number of individuals of all species recorded separately. Principal Component Analysis was utilised to show the relation among treatments and the weed spectrum. This showed the distribution of species among 19 plant families. Annual blue grass (Роа апnиа) ranked as the most abundant winter weed with an index value of 34.9. Yellow nut sedge (Cyperus esculentus) ranked as the most abundant summer weed with a value of 74.8. The summer weed gallant soldier (Galinsoga parviflora) showed strong associations with some treatments. Several treatments caused effective suppression of weeds with which no winter weed associations could form. Persistent and troublesome weed communities may be managed non-chemically by smother cropping strategies by integrating zero-tillage; legume based cropping mixtures, brush cutting and rotary mowing with flail heads to produce biomass mulches. This could promote more desirable weed communities (low competitiveness) and suppress noxious weeds (highly competitive).

Keywords: biomass mulches, brush cutting, flail heads, rotary mowing, weed suppression, zero-tillage 


\section{Inleiding}

Ondanks die toediening van onkruiddoders en ander beheermaatreëls, bly onkruid een van die belangrikste knelpunte tydens gewasverbouing, aangesien dit verantwoordelik is vir beduidende opbrengsverliese en lae kwaliteit (Campiglia et al., 2018). Dit kan boonop die oesproses en landbou-chemiese toediening belemmer (McCully et al., 1991) en oesopbrengs beïnvloed op grond van spesiesamestelling en digtheid (Kropff et al., 1992). Onkruidspesies in landbougewasse kompeteer met plante om water, voedingstowwe, lig, en ruimte. Dit huisves ook peste en plae wat die gewas kan beïnvloed (McCully et al., 1991).

Aan die positiewe kant is bewys dat onkruidflora grondvrugbaarheid kan bevorder, gronderosie en meganiese verdigting kan voorkom en as 'n bron van organiese materiaal en stikstof (Juarez-Escario et al., 2017), asook as natuurlike teenvoeter van peste en plae, (Cicuzza et al., 2012) kan dien. Boonop dra onkruidspesies by tot die verhoging van die biodiversiteit van landbou-ekosisteme (Mas et al., 2007) en lewer ekosisteemdienste, soos die behoud van bestuiwers (Garcia \& Mifiarro, 2014).

Vorige studies het aangedui dat bestuurspraktyke die onkruidspektrum kan beïnvloed ten opsigte van samestelling, verskeidenheid (Juarez-Escario et al., 2017) en die oorvloedigheid van individuele spesies (Ferrara et al., 2015). Die teenwoordigheid van elke onkruidpopulasie in 'n bewerkte land is die resultaat van ekologiese reaksies teenoor vorige bestuurspraktyke, grondeienskappe van die area en die streeksklimaat (Andersson \& Milberg, 1998). Die onkruidspektrum weerspieël ook die gevolge van plaaslike weersomstandighede soos gesien in die voorkoms, oorlewing en mededingingsvermoë daarvan (Milberg et al., 2000).

Landboubestuursaksies, sowel as plaaslike omgewingstoestande, selekteer vir of teen spesifieke eienskappe en bepaal dus watter onkruidspesies in 'n gegewe agro-ekosisteem kan oorleef (Navas, 2012). Meer intensiewe gewasverbouing word byvoorbeeld gekenmerk deur die verhoogde beskikbaarheid van hulpbronne en 'n verhoogde frekwensie en/ of intensiteit van versteuring word deur onkruide ondervind. Hierdie toestande selekteer vir eienskappe wat onkruide in staat stel om beskikbare hulpbronne te benut om hul lewenssiklus binne 'n kort tydsverloop tussen versteurings te maksimaliseer (Garnier \& Navas, 2012). Daarbenewens bied gewasse en bestuurspraktyke verskillende groeitoestande aan onkruide (Doucet et al., 1999) en dien dit dus as 'n siftingsproses wat die samestelling van onkruidpopulasies bepaal volgens hul funksionele eienskappe, soos winter- of somergroeiseisoen en eenjarige of meerjarige groeiwyse (Gaba et al., 2017). By die skadelikste onkruide,byvoorbeeld,isplantdatums, gewasopeenvolging, bossiekap en daarna fynkap met 'n deklaagimplement, gebruik om die kompetisie-vermoë spesifiek te rig op verskillende groeistadiums en ook die ondergrondse bergingsvermoë van koolhidraat-reserwes van uintjies (Wedryk \& Cardina, 2012).

Onderdrukking van skadelike onkruide kan effektief bereik word deur smoorgewasse wat die potensiaal het om biomassa vinnig te produseer (Wedryk \& Cardina, 2012). Smoorgewasse is lewende plante wat in 'n enkel stand of as plantmengsels verbou word om die ontkieming, groei en voortplanting van ongewenste plante deur middel van hulpbronkompetisie vir groeifaktore te verminder (Wedryk \& Cardina, 2012). Boonop kan die gebruik van 'n smoorgewasmengsel meer effektief wees vir onderdrukking van individuele spesies as gevolg van die benutting van verskillende bo- en onder-grondse groeinisse deur die verskillende spesies (Linares et al., 2008). Gewasmengsels wat peulgewasse insluit en wat 'n hoë hoeveelheid allelochemikalieë produseer, blyk geskik te wees vir onkruidonderdrukking deur middel van plantreste (Ferreira \& Reinhardt, 2010). Verder kan smoorgewasspesies wat verskillend aangepas is, beter meeding tydens die verskillende groeistadiums van onkruid (Wedryk \& Cardina, 2012).

Die groei van smoorgewasse kan beëindig word deur dit plat te sny met 'n bossie-kapper, gevolg deur die fynkap van plantreste (biomassa) met 'n deklaagimplement om 'n deklaag te vorm wat benut kan word om onkruidonderdrukking tydens wisselbou te bewerkstellig (Wedryk \& Cardina, 2012). 'n Smoorgewasmengsel wat 'n hoë hoeveelheid biomassa produseer en daarna fyngekap word met 'n deklaagimplement, is verder ook 'n nie-chemiese landboupraktyk. Boonop behoort smoorgewaspraktyke en gewasopeenvolging soveel verskeidenheid moontlik in te sluit om die ontkieming, lewenssiklusse en saadproduksie van onkruidspesies te ontwrig. Hierdie praktyke in kombinasie met aanvanklike beperkte onkruiddoder-toedienings, is geïntegreerd in hierdie studie op George aangewend om die effek daarvan op die onkruidspektrum en verwantskappe daarmee te evalueer.

$\mathrm{Na}$ aanleiding van 'n versoek deur die Hoofdirektoraat: Ondersteuning en Ontwikkeling van Landbouers, WesKaapse Departement van Landbou, is 'n veldproef van stapel gestuur om die samestelling van onkruidspektrums te assesseer en om eko-vriendelike onkruidonderdrukkende strategieë op die groenteplaas van die Departement van Korrektiewe Dienste op George (-33.979202, 22.446229) te evalueer. Dit is hipoteties gestel dat winter-smoorgewasse wat groothoeveelhedebiomassa in'n geen-bewerkingstelsel produseer en wat benut word deur dit plat te sny, daarna fyn te kap met 'n deklaagimplement om 'n deklaag te vorm en in die somer opgevolg word met die aanplant van 'n smoorgewas, onkruidontkiemng en ontwikkeling negatief sou beïnvloed. Verder is dit gepostuleer dat gewasmengsels met 'n peulgewas-komponent ook die grootste hoeveelheid biomassa sou oplewer en die grootste onkruid-onderdrukking teweeg sou bring deurdat onkruidsoorte aan 'n sterk siftingsproses onderhewig sou wees. Daar is ook 
verwag dat ' $n$ sterk siftingsproses vir spesifieke funksionele onkruidtipes sou selekteer, dit wil sê díe wat oor die nodige eienskappe beskik om die sifting te oorleef. Dit sou onkruidspesies met 'n lae planthoogte of 'n platrankende groeiwyse insluit wat onder verminderde lig-intensiteit kan groei omdat dit oorskadu sou word deur gewasse met 'n hoë planthoogte of dik deklae (MacLaren et al., 2019). Hierdeur sou die relatiewe digtheid van meer skadelike onkruidsoorte, soos byvoorbeeld geeluintjies (Cyperus esculentus) verminder kon word.

Aangesien daar geen gedetailleerde inligting oor die heersende onkruidflora op George is nie, was die hoofdoel van hierdie studie om die spesie-samestelling van die onkruidspektrum te beoordeel om sodoende 'n oorvloedigheids-indeks te bepaal. Tweedens was die doelwit om die assosiasies van die onkruidspektrum na behandeling met onderdrukkende verbouingstrategieë, te bepaal.

\section{Materiaal en metodes}

'n Veldeksperiment is uitgevoer op die groenteplaas van die Departement van Korrektiewe Dienste op George, WesKaap. Voordat die veldeksperiment 'n aanvang geneem het, is twee onkruidassesserings vir onderskeidelik winteren somer-onkruide, onderneem. Hierdie assesserings is óf gedurende die eerste week van September vir winteronkruid, óf die eerste week van Maart, vir somer-onkruid uitgevoer. Dit is die tydstip waarop alle eenjarige seisoenale onkruidsoorte normaalweg fisiologiese volwassenheid bereik en ook blom, wat dus die identifikasie daarvan vergemaklik. Hierdie assesserings het as 'n basislyn gedien en is na behandeling gebruik om die verwantskappe van die onkruidspektrum met betrekking tot onderdrukkende verbouingstrategieë, te taksonomeer.

\section{Klimaat en grond}

Hierdie gebied val binne die oseaniese klimaatsone met 'n gemiddelde jaarlikse langtermyn reënneerslag van 715 $\mathrm{mm}$. Dit is redelik eweredig oor die jaar versprei, maar met 'n toename in die laat winter en lente. Die gemiddelde daaglikse maksimum en minimum temperature wissel tussen $26^{\circ} \mathrm{C}$ en $8{ }^{\circ} \mathrm{C}$. Omdat duidelike groeiseisoene met betrekking tot dagliglengte en -temperatuur vir beide eenjarige winter- en someronkruide onderskei word, is data so aangeteken en ook afsonderlik ontleed.

Die grondtipe van die lokaliteit is geklassifiseer as 'n fyn, sanderige leem-dupleks of podzol (Soil Classification Working Group, 1991; Swanepoel et al., 2015), ook bekend as Alfisols (Soil Survey Staff, 2003). Die grond is redelik goed gedreineer met ' $\mathrm{n} \mathrm{pH}$ van 5.7, organiese materiaalinhoud van $3.1 \%$, en die beskikbare $\mathrm{P}$ en $\mathrm{K}$ is onderskeidelik 19.6 en $54.3 \mathrm{mg} / \mathrm{kg}^{-1}$ grond. Die lokaliteit was reeds vir 30 jaar lank onder konvensionele groenteverbouing, voordat die veldproef in aanvang geneem het.

\section{Grondvoorbereiding}

$\mathrm{Na}$ die aanvanklike onkruidassesserings, was die hele lokaliteit se grond voorberei deur ' $n$ skottelbewerking en opgevolg met 'n Kongskilde tandimplement om 'n fyn saadbed daar te stel. Hierna en tot aan die einde van die studie is dit behandel as ' $n$ geen-bewerkings-eksperiment met minder as $30 \%$ grondversteuring. Die enigste uitsondering was tydens die aanplant van gewasse met 'n Aichison-planter wat minimale grondversteuring veroorsaak het. Na gewasaanplanting is die hele lokaliteit met ' $n$ landbouroller gerol om goeie kontak tussen grond en saad te verseker. Gedurende die eksperiment het beperkte trekkerverkeer oor die hele gebied die toediening van onkruiddoders, bossiekap van gewasmengsels en die opvolg daarvan met ' $n$ deklaagimplement om sodoende die biomassa fyn te kap, ingesluit.

\section{Landbou-chemiese (onkruiddoder) toediening}

Om die oorweldigende swaar besmetting van geeluintjies tot hanteerbare vlakke te verminder, is die onkruiddoder halosulfuron (200 g aktiewe bestanddeel $/ \mathrm{ha}^{-1}$ ) in die tweede en derde jaar van die eksperiment, gedurende die laaste week van Maart, toegedien. Vir algemene onkruidbeheer in jare twee en drie, is toedienings van beide glifosaat (450 g aktiewe bestanddeel/ $/ \mathrm{ha}^{-1}$ ) in die tweede week van April en paraquat/diquat (200 g aktiewe bestanddeel $/ \mathrm{ha}^{-1}$ ) in die derde week van Oktober, gedoen. Die eksperiment is andersins op ' $n$ wyse van geenbewerking hanteer en bestuur sonder die gebruik van plaagdoders of kunsmisstowwe.

TABEL 1: Opsomming van gewasopeenvolgingsreekse wat op George benut was nadat die voorafgaande onkruidassessering afgehandel is

\begin{tabular}{l|l|l|l|l|l|l|l|l}
\hline & \multicolumn{2}{|c|}{ Jaar 1 } & \multicolumn{2}{c|}{ Jaar $\mathbf{2}$} & \multicolumn{2}{c|}{ Jaar 3 } & Jaar 4 \\
\hline Behandeling & Winter & Somer & Winter & Somer & Winter & Somer & Winter \\
\hline SRB (1) & Onbehandel & Onbehandel & Saia hawer & Tefgras & Rog & Somer \\
RSR (2) & Onbehandel & Onbehandel & Rog & Tefgras & Saia hawer & Tefgras & Braco mosterd + Wieke & Tefgras \\
SRM (3) & Onbehandel & Onbehandel & Saia hawer + Lupiene & Tefgras & Rog + Serradella & Tefgras & Rog + Wieke \\
RBS (4) & Onbehandel & Onbehandel & Rog + Serradella & Tefgras & Braco mosterd & Tefgras & Braco mosterd \\
BSR (5) & Onbehandel & Onbehandel & Braco mosterd & Tefgras & Saia hawer + Lupiene & Tefgras & Saia hawer + Lupiene \\
SBR (6) & Onbehandel & Onbehandel & Saia hawer + Serradella & Tefgras & Braco mosterd + Lupiene & Tefgras & Rog + Lupiene \\
BRB (7) & Onbehandel & Onbehandel & Braco mosterd + Lupiene & Tefgras & Rog + Wieke & Tefgras & Tefgras & Braco mosterd + Lupiene \\
KLE (8) & Onbehandel & Onbehandel & Kontrole & Kontrole & Kontrole & Tefgras & Kontrole & Kontrole \\
\end{tabular}




\section{Veldeksperiment en behandelings}

Behandelings is uitgelê in 'n ewekansige blokontwerp met agt behandelings van afsonderlike dekgewasse en peulgewasmengsels (Tabel 1). Vier herhalings is gebruik en die afmetings van individuele persele was $30 \mathrm{~m} \times 4 \mathrm{~m}$. Die kontrole persele wat nie behandel was nie, is die hele jaar onversteurd gelaat, behalwe in Maart en September toe dit elke keer platgesny was met 'n bossiekapper. Dit was gedoen om onkruidsaadproduksie en sekondêre onkruidbesmettings te beperk. Winter smoorgewasse en peulgewasmengsels is deurgaans gedurende die laaste week van April, voor die verskyning van die winteronkruide, aangeplant. Die aanplant van tefgras het deurgaans gedurende die derde week van November plaasgevind wanneer die langtermyn gemiddelde daaglikse minimum temperatuur $15^{\circ} \mathrm{C}$ in hierdie gebied bereik word. Wisselboustelsels en gewasopeenvolging word in Tabel 1 aangedui. SRB (Behandeling 1) byvoorbeeld, het bestaan uit die volgende opeenvolgende produksie-praktyke wat vanaf Jaar 2 en tot en met Jaar 4 benut was: onkruiddodertoediening - saia hawer - bossiekap - deklaagbewerking - onkruiddodertoediening - tefgras - deklaagbewerking (Jaar 2); onkruiddodertoediening - rog - bossiekap - deklaagbewerking onkruiddodertoediening - tefgras - deklaagbewerking (Jaar 3); Braco mosterd + wieke - bossiekap - deklaagbewerking - tefgras - deklaagbewerking (Jaar 4) (Tabel 1).

Die aanplantingsdatum van die wintergewasse is so gekies omdat dit inpas tussen die rustende toestand van geeluintjies en afsterwing van eenjarige someronkruide, en voor die opkoms van die meeste eenjarige winteronkruide. Soortgelyk daaraan was tefgras in die somer aangeplant ná die afsterwing van eenjarige winteronkruide en voor die verskyning van geeluintjies en someronkruide. Albei plantdatums was ook geskeduleer om drie weke na die uitdroging van die gewasreste en nadat dit fyngekap was met ' $n$ deklaagimplement, plaas te vind. Dieselfde persele is elke somer met slegs tefgras beplant teen ' $n$ saaidigtheid wat met $20 \%$ verhoog is om onkruidonderdrukkingsvermoë te verhoog. Wedryk \& Cardina (2012) het waargeneem dat die gebruik van gewasse wat 'n hoë produksietempo van biomassa het wanneer uintjie se koolhidraatreserwes laag is, ' $\mathrm{n}$ effektiewe strategie kan wees om hierdie spesifieke onkruid te onderdruk. As 'n somersmoorgewas is tefgras met sy sterk kompeteervermoë aangepas by warmer temperature en in staat om 'n mededingende plantestand te vorm wat hoë biomassa-produksie oplewer wanneer geeluintjies aktief groei.

Alle smoorgewasbehandelings is gedurende die eerste week van September met 'n bossiekapper platgesny om te voorkom dat die gewasse wat volwassenheid en optimale biomassa-produksie bereik het, saad stort. As gevolg van die hoër humiditeit en die stadiger uitdroog van gewasreste gedurende September, het die fynkap van biomassa met 'n deklaagimplement, 'n maand later in Oktober gevolg. Hierdie praktyke het ten doel gehad om die periode van onkruidonderdrukking te verleng deur middel van 'n digte deklaag. Tefgras is nie platgesny nie, maar in die derde week van Maart met slegs ' $n$ deklaagimplement fyngekap. Die gebruik van 'n deklaagimplement om sodoende oesreste in fyner deeltjies op te kap, is gedoen om 'n egalige verspreiding van plantbiomassa te verseker en die ontbinding daarvan te bespoedig. Tydens die daaropvolgende gewasaanplanting is gevolglik min steurnisse weens hompe plantreste ondervind. Aangesien die fynkap van biomassa met ' $n$ deklaagimplement die ontbindingsproses versnel, was voedingsstofsirkulering oënskynlik voldoende en is geen tekortsimptone in gewasse se biomassaproduksie gedurende die hele proefperiode waargeneem nie.

Die wintersmoorgewasse wat benut was, is saia hawer (Avena strigosa Schreb.), lupiene (Lupinus albus L.), rog (Secale cereale L.), Braco mosterd (Sinapis alba L.), wieke (Vicia spp.) en pienk serradella (Ornithopus sativus Brot.). Tefgras (Eragrostis tef (Zucc.) Trotter) is as enkelgewas in die somer aangeplant. Die samestelling van die gewasse en gewasmengsels en die plantdigthede daarvan word in Tabel 2 aangedui.

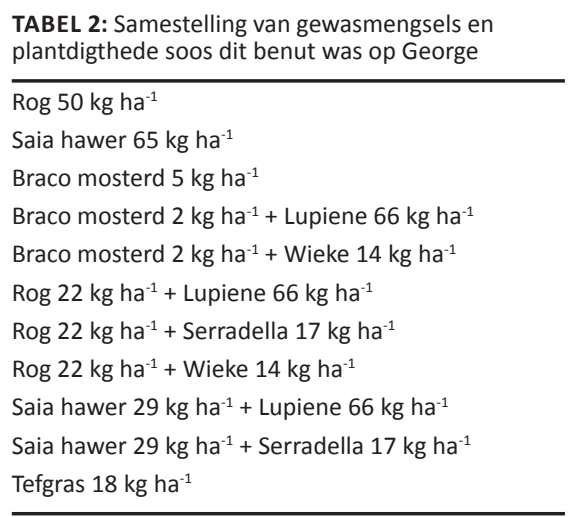

\section{Data-ontledings}

Onkruid is in elke perseel gekwantifiseer op grond van «n aangepaste metode wat deur McCully et al. (1991) beskryf is. Assesserings is oor die hele proefarea gedoen deur veertig kwadrante van $0.25 \mathrm{~m}^{2}$ elk in 'n omgekeerde $\mathrm{W}$-patroon te rangskik. Tien kwadrante is eweredig langs elke transeksie geplaas. Na die identifikasie by elke bemonsteringspunt is die aantal individue van alle onkruidspesies binne 'n $0.25 \mathrm{~m}^{2}$ kwadrant $(0.5 \mathrm{~m} \times 0.5 \mathrm{~m})$ afsonderlik aangeteken.

Die samestelling van die onkruidflora is ontleed, volgens die metodes van McCully et al. (1991) en Shrestha et al. (2001), deur die relatiewe oorvloedigheid van elke spesie oor die proefgebied te bereken om die oneweredige en kolkol aard van onkruidpopulasies te te bowe te kom. Hierdie waarde het geen eenhede nie (McCully et al., 1991) en is daarom 'n indeks (Shrestha et al., 2001) wat gebruik word om die bydrae van individuele spesies in die onkruidflora aan 'n rangorde te koppel en om die bydrae van groepe spesies te vergelyk as volg: 
Relatiewe oorvloedigheid $=$ (relatiewe frekwensie + relatiewe digtheid);

Waar relatiewe frekwensie $=$ die verhouding van die kwadrante waarin die spesie teenwoordig was per perseel, gedeel deur die totale frekwensie van alle spesies;

En relatiewe digtheid = aantal plante vir 'n gegewe onkruidspesie binne die kwadrante per perseel, gedeel deur die totale aantal onkruide binne kwadrante oor die hele monsternemingsgebied.

Vervolgens is die invloed van behandelings op die spesiesamestelling van die onkruidspektrum bepaal (SAS, 2008). Alle onkruidspesies wat tydens die twee monsternemings aangeteken was, is ontleed met behulp van Hoofkomponent Analise (HKA) (Ter Braak \& Verdonschot, 1995). Die HKA benut die Pearson korrelasie-matriks as inset. HKA voorsien 'n beknopte oorsig van 'n datastel en is 'n kragtige metode om data-neigings en -patrone te herken. Die tellinggrafiek toon aan hoe behandelings in verband staan met mekaar as dit gebaseer word op die populasie-samestelling van die onkruidspektrum. Behandelings met soortgelyke profiele kom digby mekaar voor op die grafiek, terwyl dié met verskillende profiele, ver uitmekaar lê.

\section{Resultate}

Waargenome onkruidsoorte behoort aan 19 plantfamilies, waarvan die Asteraceae 8 spesies bygedra het en dus die belangrikste was (Tabel 3). Dit is gevolg deur 'n ander belangrike plantfamilie wat veldtaxa betref, naamlik Poaceae, wat deur vyf spesies verteenwoordig was. Drie spesies is waargeneem vir elk van die Brassicaceae, Caryophyllaceae en Polygonaceae, terwyl twee spesies aan beide die Amaranthaceae en Solanaceae behoort het (Tabel 3). Al hierdie plantfamilies is spesieryk, waarvan talle onkruide is. Hierdie lokaliteit met sy oseaniese klimaat is onderhewig aan voortdurende grondversteuring en besproeiing gedurende droër tydperke. Die gevolg is dat grond- en omgewingstoestande ' $n$ aansienlike bydrae lewer tot die totale onkruidspektrum, wat uiteindelik ' $n$ eweredige verspreiding toon tussen die winter- en somergroeiseisoene.

TABEL 3: Botaniese naam, plantfamilie, gewone naam en groei-seisoen van eenjarige onkruidspesies aangeteken tydens ' $n$ ondersoek wat ' $n$ veldeksperiment by George voorafgegaan het

\begin{tabular}{|c|c|c|c|}
\hline Botaniese naam & Plantfamilie & Gewone naam & Groei-seisoen \\
\hline Amaranthus hybridus $\mathrm{L}$. & Amaranthaceae & Kaapse misbredie & somer \\
\hline Arctotheca calendula (L.) Levyns & Asteraceae & gousblom & winter \\
\hline Anagallis arvensis $\mathrm{L}$. & Primulaceae & blouselblommetjie & winter \\
\hline Bidens pilosa $\mathrm{L}$. & Asteraceae & gewone knapsekêrel & somer \\
\hline Brachiaria eruciformis (Sm.) Griseb. & Poaceae & litjie-sinjaalgras & somer \\
\hline Capsella bursa-pastoris (L.) Medik. & Brassicaceae & herderstassie & winter \\
\hline Cerastuim capense Sond. & Caryophyllaceae & Kaapse cerastium & winter \\
\hline Chenopodium album $\mathrm{L}$. & Amaranthaceae & wit hondebossie & somer \\
\hline Conyza bonariensis (L.) Cronq. & Asteraceae & klein skraalhans & somer \\
\hline Coronopus didymus (L.) Sm. & Brassicaceae & peperkruid & winter \\
\hline Cyperus esculentus L. & Cyperaceae & geeluintjie & somer \\
\hline Datura stramonium L. & Solanaceae & stinkblaar & somer \\
\hline Digitaria sanguinalis (L.) Scop. & Poaceae & kruisvingergras & somer \\
\hline Echium plantagineum L. & Boraginaceae & pers-echium & somer \\
\hline Eleusine coracana (L.) Gaertn. & Poaceae & jong osgras & somer \\
\hline Emex australis Steinh. & Polygonaceae & Kaapse duwweltjie & winter \\
\hline Erodium moschatum (L.) L’Hér. & Geraniaceae & turksnaels & winter \\
\hline Fumaria muralis W.D.J. Koch. & Papaveraceae & duiwe kerwel & winter \\
\hline Galinsoga parviflora Cav. & Asteraceae & knopkruid & somer \\
\hline Gnaphalium subfalcatum Cabrera. & Asteraceae & roerkruid & somer \\
\hline Hypochaeris glabra L. & Asteraceae & harige skaapslaai & winter \\
\hline Lactuca serriola L. & Asteraceae & wilde slaai & somer \\
\hline Lamium amplexicaule L. & Lamiaceae & henbit & winter \\
\hline Lolium multiflorum Lam. & Poaceae & Italiaanse raaigras & winter \\
\hline Malva parviflora $\mathrm{L}$. & Malvaceae & kiesieblaar & winter \\
\hline Nicandra physalodes (L.) Gaertn. & Solanaceae & baster appelliefie & somer \\
\hline Oenothera parodiana Munz. subsp. parodiana & Onagraceae & nagblom & somer \\
\hline Oxalis pes-caprae L. & Oxalidaceae & geelsuring & winter \\
\hline Plantago lanceolata $\mathrm{L}$. & Plantaginaceae & smal weëblaar & winter \\
\hline Poa annua L. & Poaceae & wintergras & winter \\
\hline Polygonum aviculare L. & Polygonaceae & voël duisendknoop & somer \\
\hline Portulaca oleracea L. & Portulacaceae & porslein & somer \\
\hline Raphanus raphanistrum L. & Brassicaceae & ramenas & winter \\
\hline Rumex crispus L. & Polygonaceae & krultongblaar & winter \\
\hline Sonchus asper (L.) Hill & Asteraceae & doring sydissel & somer \\
\hline Spergula arvensis $\mathrm{L}$. & Caryophyllaceae & sporrie & winter \\
\hline Stellaria media (L.) Vill. & Caryophyllaceae & sterremuur & winter \\
\hline Tribulus terrestris L. & Zygophyllaceae & volstruis duwweltjie & somer \\
\hline
\end{tabular}


Bogenoemde 19 plantfamilies het bestaan uit ' $n$ totaal van 38 verskillende eenjarige onkruidspesies. Hiervan is 32 spesies tweesaadlobbiges $(84.2 \%)$, vyf spesies eensaadlobbiges $(13.2 \%)$, terwyl die Cyperaceae een spesie $(2.6 \%)$ bygedra het. Die verspreiding van spesies oor die 19 plantfamilies is buite verhouding verteenwoordig deurdat $57.9 \%$ van die spesies afkomstig is van vyf plantfamilies en die oorblywende $42.1 \%$ van 14 plantfamilies. Hiervan is 12 plantfamilies deur slegs 'n enkele spesie verteenwoordig (Tabel 3). In totaal is vier spesies inheems en 34 uitheems. Inheemse onkruidspesies sluit in gousblom (Arctotheca calendula) Kaapse serastium (Cerastuim capense) Kaapse duwweltjie (Emex australis) en geelsuring (Oxalis pes-caprae). 'n Gelyke getal van 19 somer- en 19 winteronkruide is geïdentifiseer. Weens die duidelike onderskeid tussen die onkruidspektrums wat by seisoenale groeitoestande aangepas was, is data vir winter- of someronkruide apart hanteer en as sodanig aangebied (Tabel 3).

Die mees algemene winteronkruid was eenjarige wintergras (Poa annua), met 'n frekwensie van $8.4 \%$. Bykomende winteronkruide wat in frekwensies van meer as $6 \%$ in die kwadrante voorgekom het, was sterremuur (Stellaria media), duiwe kerwel (Fumaria muralis), ramenas (Raphanus raphanistrum), sporrie (Spergula arvensis) en winter duwweltjie (E. australis) (Tabel 4).

As eenjarige winteronkruid wat die wydste verspreiding getoon het, is wintergras ( $P$. annua) die hoogste op die oorvloedigheidsranglys met 'n waarde van 34.9 en 'n relatiewe digtheid van $26.6 \%$. Sterremuur (S. media), duiwe kerwel (F. muralis), ramenas ( $R$. raphanistrum), sporrie (S. arvensis) en winter duwweltjie (E. australis) se relatiewe digthede was almal meer as $5 \%$ (Tabel 4 ). Dit is ook die winteronkruide met die hoogste posisie betreffende relatiewe oorvloedigheid met syfers wat wissel van 11.8 18.1. Frekwensies van die oorblywende 13 onkruide wissel van $1.0 \%$ tot $5.6 \%$, met die ooreenstemmende relatiewe digthede se waardes tussen $0.5 \%$ en $4.4 \%$ (Tabel 4 ).

As someronkruid met die wydste verspreiding, is geeluintjie (C. esculentus) bo-aan die ranglys wat relatiewe oorvloedigheid aandui (Tabel 5). Dit is die algemeenste onkruid met die grootste frekwensie van $8.8 \%$. Ander someronkruide wat in frekwensies van meer as $6 \%$ in die kwadrante voorkom, is knopkruid (Galinsoga parviflora), voël duisendknoop (Polygonum aviculare), klein skraalhans (Conyza bonariensis), Kaapse misbredie (Amaranthus hybridus), litjie-sinjaalgras (Brachiaria eruciformis), wit hondebossie (Chenopodium album) en pers-echium (Echium plantagineum). Dit is ook die someronkruide wat die hoogste op die ranglys voorkom wat betref relatiewe oorvloedigheid, met waardes wat tussen 8.2 en 10.7 wissel (Tabel 5). Die frekwensie van die 11 oorblywende someronkruide is tussen $1.1 \%$ tot $5.5 \%$ (Tabel 5).

$\mathrm{Na}$ die toepassing van alle behandelings, het die finale onkruidbeoordeling en Hoofkomponent Analise (HKA) gevolg. HKA word in tellinggrafieke uitgebeeld. Die eerste en tweede asse van die tellinggrafiek dui 'n variasie aan van $44.68 \%$ van die assosiasie met die somer onkruidspektrum (Figuur 1). Knopkruid (G. parviflora) het sterk verwantskappe met behandelings SRB (1), RSR (2) en SRM (3) getoon en het in die kwadrant links onder gegroepeer (Figuur 1). Hierdie onkruid kom egter aan die teenoorgestelde kant van die grafiek se middelpunt as die kwadrant regs bo voor, en is dus ortogonaal nie net met klein skraalhans (C. bonariensis) nie, maar ook met alle onkruide wat daar saamgroepeer.

Alle someronkruide, met die uitsondering van twee breëblaaronkruide, is doeltreffend onderdruk deur beide behandelings RBS (4) en BSR (5). Voorgenoemde behandelings het soortgelyke onkruidprofiele. Die twee dominerende onkruide wat daarin voorkom, naamlik persechium (E. plantagineum) en nagblom (O. parodiana), het 'n

TABEL 4: Botaniese naam, frekwensie, relatiewe digtheid en relatiewe oorvloedigheid van eenjarige winteronkruide waargeneem tydens ' $n$ assessering wat ' $n$ veldeksperiment by George voorafgegaan het

\begin{tabular}{|c|c|c|c|}
\hline Botaniese naam & Frekwensie \% & Relatiewe digtheid \% & Relatiewe oorvloedigheid \\
\hline$\overline{P o a}$ annua $\mathrm{L}$. & 8,4 & 26,6 & 34,9 \\
\hline Stellaria media (L.) Vill. & 6,6 & 11,5 & 18,1 \\
\hline Fumaria muralis W.D.J. Koch. & 5,9 & 9,5 & 15,4 \\
\hline Raphanus raphanistrum L. & 7,0 & 7,8 & 14,7 \\
\hline Arctotheca calendula (L.) Levyns & 5,6 & 7,9 & 13,5 \\
\hline Spergula arvensis $\mathrm{L}$. & 6,3 & 6,4 & 12,7 \\
\hline Emex australis Steinh. & 6,3 & 5,5 & 11,8 \\
\hline Hypochoeris glabra L. & 5,6 & 4,4 & 10,0 \\
\hline Coronopus didymus (L.) Sm. & 5,9 & 4,0 & 9,9 \\
\hline Capsella bursa-pastoris (L.) Medik. & 5,9 & 3,4 & 9,3 \\
\hline Erodium moschatum (L.) L’Hér. & 5,6 & 1,9 & 7,5 \\
\hline Cerastuim capense Sond. & 5,2 & 1,9 & 7,1 \\
\hline Anagallis arvensis $\mathrm{L}$. & 4,9 & 2,1 & 7,0 \\
\hline Oxalis pes-caprae L. & 5,2 & 1,8 & 7,0 \\
\hline Rumex crispus L. & 4,9 & 1,6 & 6,5 \\
\hline Lolium multiflorum Lam. & 3,5 & 1,8 & 5,2 \\
\hline Malva parviflora L. & 3,5 & 0,8 & 4,2 \\
\hline Plantago lanceolata L. & 2,8 & 0,8 & 3,5 \\
\hline Lamium amplexicaule L. & 1,0 & 0,5 & 1,5 \\
\hline
\end{tabular}


TABEL 5: Botaniese naam, frekwensie, relatiewe digtheid en relatiewe oorvloedigheid van eenjarige someronkruide waargeneem tydens ' $n$ assessering wat ' $n$ veldeksperiment by George voorafgegaan het

\begin{tabular}{|c|c|c|c|}
\hline Botaniese naam & Frekwensie \% & Relatiewe digtheid \% & Relatiewe oorvloedigheid \\
\hline Cyperus esculentus L. & 8,8 & 66,1 & 74,8 \\
\hline Galinsoga parviflora Cav. & 7,7 & 3,0 & 10,7 \\
\hline Polygonum aviculare L. & 6,9 & 3,5 & 10,5 \\
\hline Conyza bonariensis (L.) Cronq. & 7,3 & 2,9 & 10,2 \\
\hline Amaranthus hybridus L. & 6,9 & 2,5 & 9,5 \\
\hline Brachiaria eruciformis (Sm.) Griseb. & 6,6 & 2,6 & 9,2 \\
\hline Chenopodium album L. & 6,2 & 2,8 & 9,0 \\
\hline Echium plantagineum $\mathrm{L}$. & 6,2 & 2,0 & 8,2 \\
\hline Digitaria sanguinalis (L.) Scop. & 5,5 & 2,3 & 7,8 \\
\hline Datura stramonium L. & 5,8 & 1,8 & 7,6 \\
\hline Portulaca oleracea L. & 5,5 & 1,5 & 6,9 \\
\hline Bidens pilosa $\mathrm{L}$. & 5,1 & 1,7 & 6,8 \\
\hline Lactuca serriola L. & 5,1 & 1,6 & 6,7 \\
\hline Gnaphalium subfalcatum Cabrera. & 4,7 & 2,0 & 6,7 \\
\hline Eleusine coracana (L.) Gaertn. & 4,4 & 1,9 & 6,3 \\
\hline Nicandra physalodes (L.) Gaertn. & 3,3 & 0,9 & 4,2 \\
\hline Sonchus asper (L.) Hill & 1,8 & 0,4 & 2,2 \\
\hline Oenothera parodiana Munz. subsp. parodiana & 1,1 & 0,2 & 1,3 \\
\hline Tribulus terrestris L. & 1,1 & 0,2 & 1,3 \\
\hline
\end{tabular}

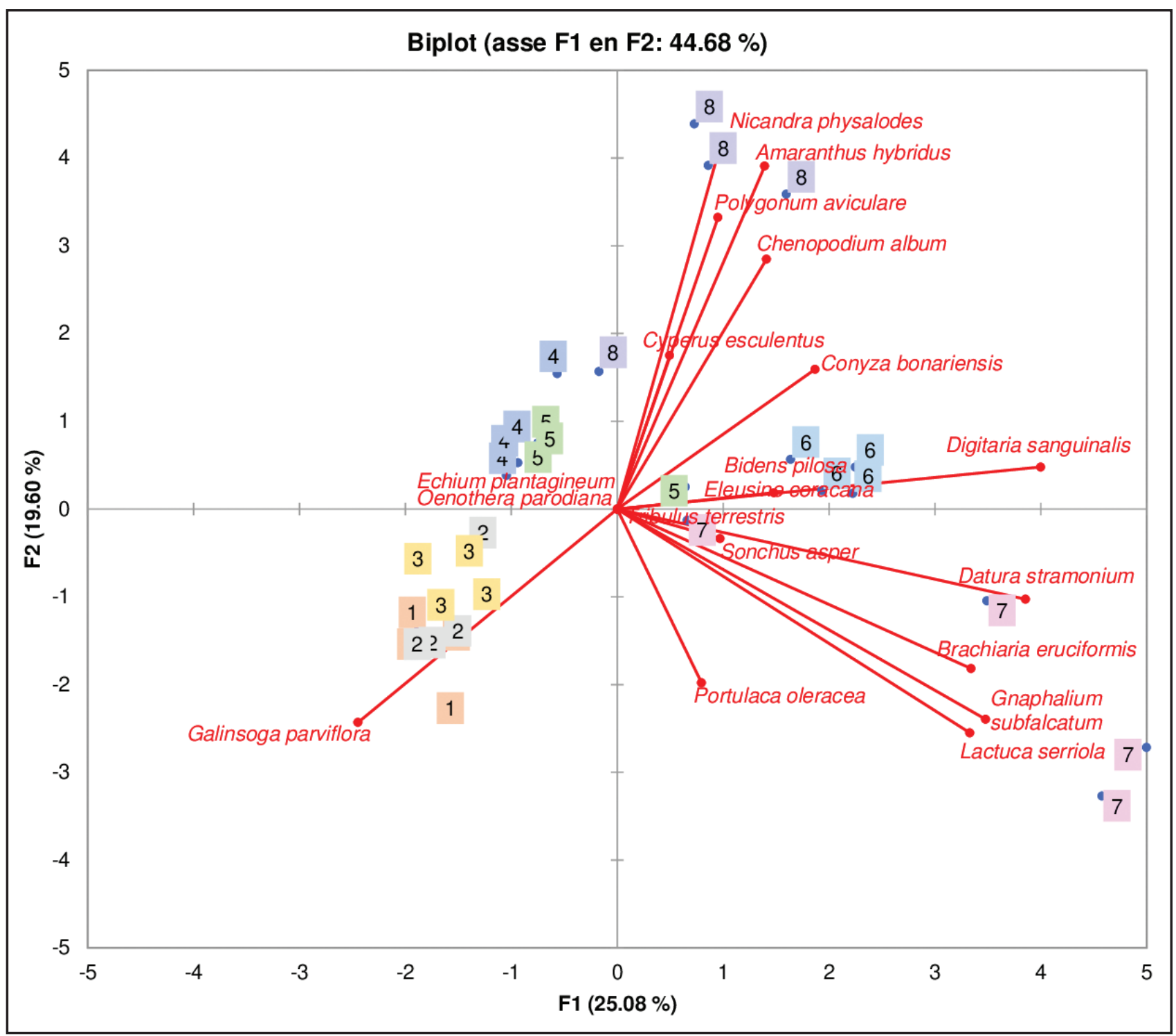

FIGUUR 1: Tellinggrafiek van die populasie-samestelling van someronkruid-spesies se finale spektrum op George, en die assosiasies daarvan met smoorgewasverbouings-praktyke wat aangedui word deur die Behandelingsnommers 1-8. 
soortgelyke groeiwyse en het swak assosiasies getoon met smoorgewas-verbouingspraktyke, soos dit toegepas is in bogenoemde twee behandelings. Daarenteen het SBR (6) daartoe gelei dat die someronkruidspesies jong osgras (E. coracana), gewone knapsekêrel (Bidens pilosa) en kruisvingergras (Digitaria sanguinalis) sterk assosiasies met mekaar getoon het en in die kwadrant regs bo saamgegroepeer het.

Behandeling BRB (7) se hoofkenmerk was dat dit die gewasmengsel Braco mosterd+lupiene twee keer oor die proeftydperk bevat het (Tabel 1). Verder is dit geassosieer met die somer-onkruidspesies volstruis duwweltjie (Tribulus terrestris), doring sydissel (Sonchus asper), stinkblaar (Datura stramonium), litjie-sinjaalgras (B. eruciformis), roerkruid (Gnaphalium subfalcatum), wilde slaai (Lactuca serriola) en porslein (Portulaca oleracea), wat almal soortgelyke profiele aangetoon het en saamgegroepeer het in die kwadrant regs onder (Figuur 1). Gegewe die afstand van die grafiek se middelpunt af en die nabyheid van datapunte binne die kwadrant, dui die voorkoms van die onkruide stinkblaar (D. stramonium), litjie-sinjaalgras (B. eruciformis), roerkruid (G. subfalcatum) en wilde slaai (L. serriola) op betekenisvolle positiewe korrelasies.

Die someronkruide geeluintiie (C. esculentus), baster appelliefie (Nicandra physalodes), voël duisendknoop ( $P$. aviculare), Kaapse misbredie (A. hybridus), wit hondebossie (C. album) en klein skraalhans (C. bonariensis), het 'n sterk verwantskap getoon met die onbehandelde kontrole. Die heersende groei-toestande aldaar het dit bevoordeel, soos uitgebeeld word in die saamgroepering daarvan in die kwadrant regs bo (Figuur 1).

Na behandeling met smoorgewas-verbouingspraktyke dui die tellinggrafiek se eerste twee asse 'n variasie aan van $59.44 \%$ van die assosiasie met die winteronkruid-spektrum (Figuur 2).

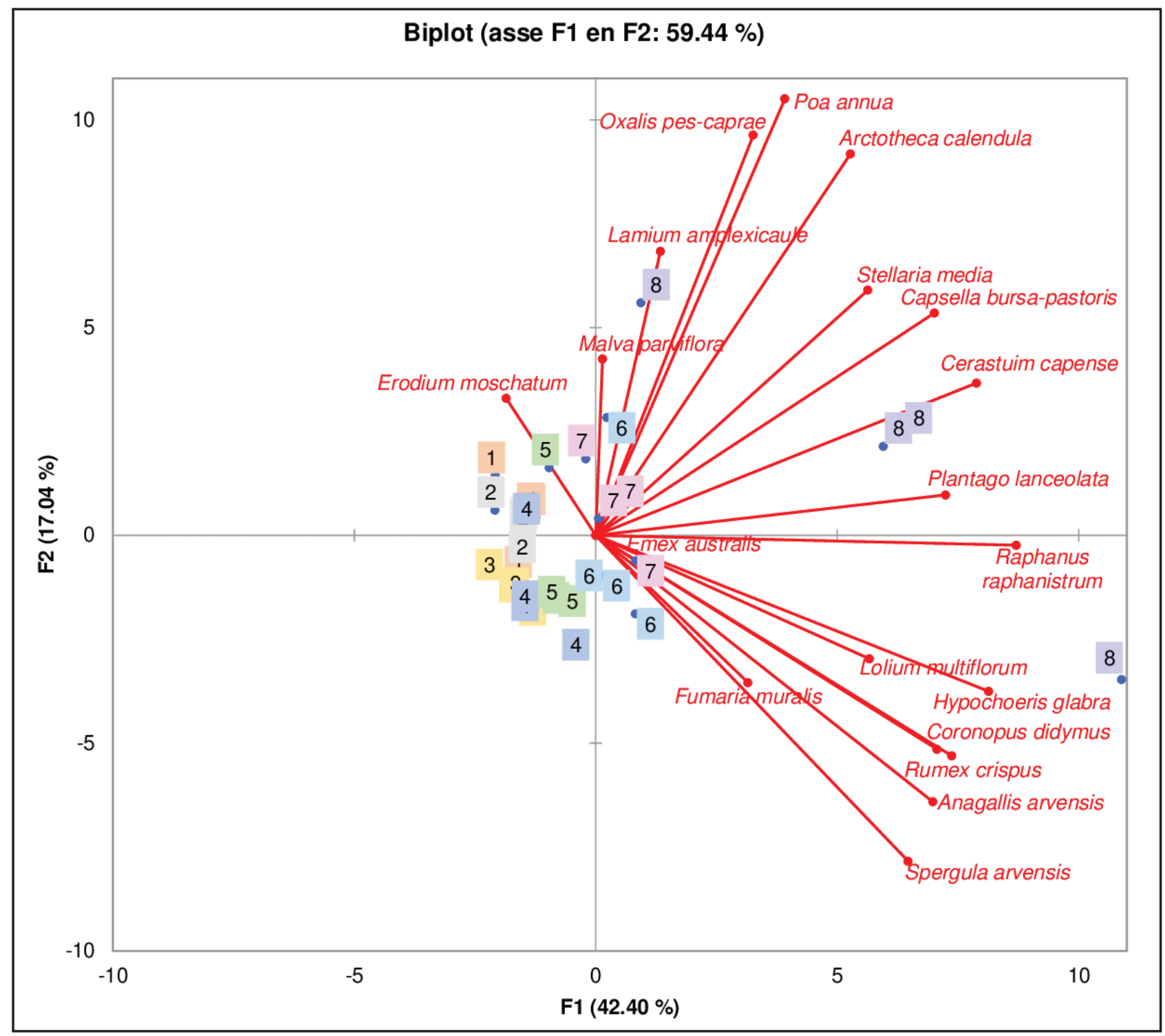

FIGUUR 2: Tellinggrafiek van die populasie-samestelling van winteronkruid-spesies se finale spektrum op George en die assosiasies daarvan met smoorgewasverbouings-praktyke wat aangedui word deur die Behandelingsnommers 1-8. 
Slegs pers-echium (E. moschatum) het 'n sterk assosiasie met behandelings SRB (1) en RSR (2) aangetoon en voordeel getrek uit die betrokke groei-toestande soos blyk uit die uitbeelding daarvan in die kwadrant links bo (Figuur 2). Hierdie onkruid is nietemin aan die teenoorgestelde kant van die grafiek se middelpunt en dus ortogonaal met duiwe kerwel (F. muralis), sporrie (S. arvensis), blouselblommetjie (A. arvensis), krultongblaar (Rumex crispus), peperkruid (Coronopus didymus), harige skaapslaai (Hypochoeris glabra) en Italiaanse raaigras (Lolium multiflorum) en gevolglik betekenisvol negatief gekorreleerd daarmee.

Behandelings SRM (3), RBS (4) en BSR (5) het doeltreffende onderdrukking tot gevolg gehad en geen winteronkruide kon assosiasies daarmee vorm nie. Eweneens was SBR (6) en BRB (7) effektief wat onkruidonderdrukking betref deurdat dit om die grafiek se middelpunt groepeer (Figuur 2) en verder geen verwantskap met onkruide aandui nie.

Volgens Figuur 2 het die winteronkruide duiwe kerwel ( $F$. muralis), sporrie (S. arvensis), blouselblommetjie (A. arvensis), krultongblaar ( $R$. crispus), peperkruid (C. didymus), harige skaapslaai (H. glabra) en Italiaanse raaigras (L. multiflorum), swak assosiasies met behandelings aangetoon. Die teendeel is dat die afstand van die grafiek se middelpunt en die nabyheid van datapunte binne die kwadrant, dui op betekenisvolle positiewe korrelasies van voorgenoemde onkruide met mekaar, soos bewys deur die saamgroepering daarvan in die kwadrant regs onder (Figuur 2).

Die onbehandelde kontrole het sterk assosiasies gevorm met die winteronkruide henbit (Lamium amplexicaule), geelsuring (O. pes-caprae), wintergras ( $P$. annua), gousblom (A. calendula), sterremuur (S. media), herderstassie (Capsella bursa-pastoris), Kaapse cerastium (C. capense) en small weëblaar (Plantago lanceolata). Hierdie onkruide het gedy onder die heersende groei-toestande waar die minimum versteuring gehandhaaf was en bossiekap slegs twee keer per jaar toegepas was. Dus het dit saamgegroepeer en word uitgebeeld in die kwadrant regs bo (Figuur 2).

\section{Bespreking en gevolgtrekkings}

Die sterk assosiasies van knopkruid (G. parviflora) met behandelings SRB (1), RSR (2) en SRM (3), dui op uiters gunstige omgewingstoestande vir die ontkieming en groei van hierdie onkruid wat dit uitermate bevoordeel het. Desnieteenstaande is dit insiggewend dat knopkruid (G. parviflora) in die teenoorstaande kwadrant as klein skraalhans (C. bonariensis) voorkom en negatief gekorreleerd is daarmee.

Klein skraalhans (C. bonariensis) word geassosieer met behandelings SBR (6) en KLE (8). SBR (6) was die enigste behandeling waar lupiene twee jaar agtereenvolgens verbou was as deel van die gewasmengsel. Die verhoogde stikstofvlakke van SBR (6) het moontlik voordelige groei- toestande vir klein skraalhans (C. bonariensis) geskep. In die geval van behandeling KLE (8) dui die onversteurde groeitoestande wat meerendeels kenmerkend was daarvan, dat die ontkieming en groei van nie net klein skraalhans $(C$. bonariensis) sterk bevoordeel is nie, maar ook alle ander onkruide wat saam daarmee 'n groepering gevorm het. Die groter verskeidenheid spesies wat kenmerkend was van hierdie behandeling, is waarskynlik die gevolg van mededinging tussen spesies en ook hoër ligintensiteit met geen skaduwees van hooggroeiende gewasse nie. Normaalweg word daar in hierdie situasies meer ligstraling ondervind weens laer planthoogtes en minder ligonderskepping, wat meer onkruidspesies bevoordeel en hul mededingendheid verhoog.

Die positiewe korrelasies van die someronkruide stinkblaar (D. stramonium), litjie-sinjaalgras (B. eruciformis), roerkruid (G. subfalcatum) en wilde slaai (L. serriola), hou verband met behandeling BRB (7) wat gunstige omgewingstoestande geskep het en dus die ontkieming en groei van die spesifieke groepering van onkruide, bevoordeel het. In teenstelling hiermee, is dit egter duidelik dat behandelings RBS (4) en BSR (5) wat in die kwadrant teenoorstaande aan BRB (7) groepeer, hierdie groep onkruide doeltreffend onderdruk het.

Wat winteronkruide betref, is behandelings SRB (1), RSR (2) en BRB (7) positief gekorreleerd met turksnaels ( $E$. moschatum). Die onkruidgroepering wat insluit duiwe kerwel (F. muralis), sporrie (S. arvensis), blouselblommetjie (A. arvensis), krultongblaar ( $R$. crispus), peperkruid (C. didymus), harige skaapslaai (H. glabra) en Italiaanse raaigras (L. multiflorum) is nie slegs negatief gekorreleerd met bogenoemde behandelings nie, maar ook met turksnaels (E. moschatum). Dit is aanduidend van turksnaels (E. moschatum) se sterk kompeteervermoë wat meegehelp het om bogenoemde groep onkruide effektief te onderdruk.

Die sterk positiewe korrelasie van knopkruid (G. parviflora) met behandelings SRB (1), RSR (2) en SRM (3) is 'n duidelike aanduiding dat praktyke soos geen-bewerking, smoorgewasverbouing met peulgewasse, platsny van die gewasse en die gebruik van 'n deklaagimplement, ideale omstandighede geskep het vir die groei van hierdie onkruid. Dit is baie waarskynlik dat 'n lae ligintensiteit en 'n bepaalde mikroklimaat onder die blaredak van gewasse, 'n groeinis tot gevolg gehad het wat knopkruid bevoordeel het, maar meer skadelike onkruide effektief onderduk het. Dit lewer verdere bewys van die impak van hierdie geïntegreerde nie-chemiese groei-onderdrukkende strategieë op onkruide. ' $n$ Verdere bewys hiervan is dat behandeling SRB (6) die grootste onderdrukking van geeluintjies (C. esculentus) by hierdie lokaliteit tot gevolg gehad het (Ferreira, 2020).

Die relatiewe digthede wat vir beide die winter- en somereenjariges in hierdie studie verkry is, dui daarop dat die lewenssiklus en fenologie van sommige van hierdie 
onkruidsoorte die rede kan wees vir hul hardnekkige voortbestaan ondanks verskeie beheerstrategieë (McCully et al., 1991). Die toenemende relatiewe digtheid van onkruidspesies wat tot die Asteraceae-plantfamilie behoort, stem ooreen met die bevindings van Van Acker et al. (2000) se ondersoek, maar wat ander resultate betref is geen toename in spesies van die Brassicaceae of enige ander onkruidfamilies gerapporteer nie. In hierdie studie daarenteen, het spesies wat behoort tot die families Primulaceae, Lamiaceae, Oxalidaceae, Caryophyllaceae, Portulacaceae en Asteraceae hul onderskeie relatiewe digthede aansienlik verhoog in die onbehandelde kontrole.

Oor die algemeen stem hierdie resultate ooreen met 'n studie deur Ruisi et al. (2015), wat aangetoon het dat onkruidstand, samestelling en digtheid ' $n$ weerspieëlling is van die vorige en huidige landboupraktyke. Verder het die resultate aangedui dat die samestelling van die onkruidflora by George ' $n$ weerspieëling is van die verskillende praktyke daar toegepas. Dit is onvermydelik dat die onkruidspektrum wat onder verskillende gewasverbouingspraktyke voorkom, in hul mededingendheid sal verskil. 'n Verdere oorweging genoem deur McCully et al. (1991), is dat ondersoeke van onkruidpopulasies nie die grootte van die onkruid in ag neem nie. Sommige onkruide is kort, klein en groei goed onder die blare-dak van gewasse en het waarskynlik 'n lae potensiaal om te kompeteer (MacLaren et al., 2019). Sommige spesies het weer 'n hoë frekwensie, digtheid en relatiewe oorvloedigheid, maar hou geen bedreiging in vir die oesproses of kompetisie vir sonlig nie. Die grootste bedreiging sou ontstaan as gevolg van mededinging vir voedingstowwe en water. Gegrond op waarneming blyk dit dat hoër groeiende gewasse met penwortels die voorkoms van hierdie onkruide onder hul blare-dak, sonder enige opbrengsverliese kan weerstaan (McCully et al., 1991).

Die reaksie van baie onkruidspesies in die huidige studie is grootliks in ooreenstemming met vroeëre verslae. Die baie lae relatiewe digtheid van Italiaanse raaigras (L. multiflorum) kan byvoorbeeld grootliks toegeskryf word aan die beoefening van geen-bewerking en die beperkte gebruik van onkruiddoders (MacLaren et al., 2019). Resultate vir Conyza spp., peperkruid (C. didymus) en herderstassie (Capsella bursa-pastoris), stem ooreen met bevindings deur Derksen et al. (1993) dat besmettings van hierdie spesies sterk geassosieer word met geen-bewerking. Onlangse bevindings deur MacLaren et al. (2019) het aangetoon dat faktore soos bespuiting met onkruiddoders en droër toestande verband hou met groter populasies van Lolium spp.. Plat gesnyde persele in natter dele word geassosieer met die inheemse onkruid geelsuring (O. pes-caprae) (MacLaren et al., 2019). Verder het MacLaren et al. (2019) bevind dat turksnaels (E. moschatum) en ramenas ( $R$. raphanistrum) 'n assosiasie toon met bewerkte persele. Daar kan aanvaar word dat wanneer geen-bewerking toegepas word, laer digthede van beide bogenoemde onkruidspesies waargeneem sou kon word. Volgens MacLaren et al., 2019), het platsny 'n groter verskeidenheid en vermeerdering van onkruide, insluitend die voorkoms van groter getalle inheemse onkruide, tot gevolg. Dit dui daarop dat die beste benadering om die mededingende potensiaal van die onkruidflora te bereik, is deur gebruik te maak van geïntegreerde bestuurspraktyke, wat platsny en die gebruik van 'n deklaagimplement, insluit.

Sommige onkruidspesies, soos wit hondebossie (C. album L.), se ontkieming hou verband met die plantdatum van gewasse (Gunton et al., 2011) en kan deurlopende versteuring weerstaan. ' $n$ Tipiese strategie om dit te oorkom is die reëlmatige saadontkieming wat deurlopend gedurende die verbouingstydperk plaasvind (Fried et al., 2012). Nagy et al. (2018) het berig dat plantdatum 'n belangrike aandrywer is van onkruidspesie-samestelling, terwyl Fried et al. (2012) dit eens was dat die teenwoordigheid van 'n verskeidenheid gewasse en tyd van verbouing, die verskeidenheid onkruidspesies van 'n gebied aansienlik kan verhoog. Die belang hiervan is dat 'n groter verskeidenheid van onkruidspesies op sy beurt lei tot 'n spesieryke omgewing met meer diversiteit en mededinging tussen spesies in onkruidgemeenskappe. MacLaren et al. (2019) het tot die gevolgtrekking gekom dat dit onvolhoubaar is om deurlopend te probeer om alle onkruide op landbougrond te beheer. In plaas daarvan moet maniere gevind word om die aantal pogings om onkruide te beheer, te verminder om die positiewe rol van onkruide in agroekosisteme te integreer.

Farooq et al. (2011) het verduidelik dat bewaringslandbou, gebaseer op minimum grondversteuring en permanente grondbedekking, 'n alternatiewe benadering is om landbou-ekosisteme te bestuur. Dit bevorder gewasproduksie, hulpbronsirkulering en omgewingsveiligheid, selfs al is onkruidbeheer een van die moeilikste uitdagings daarvan. Ondersoeke wat gewasverbouingstelsels evalueer is dus noodsaaklik om insig te verkry oor die invloed daarvan op die onkruidspektrum en spesiediversiteit (Halde et al., 2015). Langtermyn veldeksperimente is veral belangrik om veranderinge in die samestelling van die onkruidspektrum te evalueer (Ruisi et al., 2015). Verder sal navorsing oor die rol van allelopatie in smoorgewasverbouing en deklae, sowel as alle aspekte van verboude ekosisteme (Ferreira \& Reinhardt, 2016) by hierdie lokaliteit, noodsaaklike inligting verskaf en die besluitneming oor onkruidbestuur verbeter.

Inligting oor die spesiesamestelling en oorvloedigheid daarvan is ' $n$ belangrike komponent van die onkruidspektrum en vir besluitneming rakende onkruidbestuur. Hardnekkige en skadelike onkruidspesies kan deur niechemiese onderdrukkende strategieë bestuur word deur die integrering van geen-bewerking, verbouing van smoorgewasse met 'n peulgewaskomponent, platsny van die gewasse, en deur dit op te volg deur die fynkap van biomassa met 'n deklaagimplement. In die konteks van plaaslike toestande by George kan dit meer wenslike 
onkruidspesies en -assosiasies bevorder wat sodoende skadelike onkruide sou kon onderdruk. Laastens sal hierdie ondersoek landbouers help om die huidige onkruidspektrum beter te verstaan en te bestuur en ook dien as ' $n$ grondslag vir toekomstige onkruidnavorsing in hierdie streek.

\section{Erkenning}

Ondersteuning en befondsing vir hierdie navorsing is verskaf deur die Wes-Kaapse Departement van Landbou. Die tegniese hulp verleen deur die Departement van Korrektiewe Dienste, George, en kollegas Z Sedeman en $\mathrm{H}$ Gerber, word opreg waardeer.

\section{Verwysings}

Andersson, T.N., Milberg, P. 1998. Weed flora and the relative importance of site, crop, crop rotation, and nitrogen. Weed Science 46, 30-38. https://doi. org/10.1017/S0043174500090135.

Campiglia, E., Radicetti, E., Mancinelli, R. 2018. Floristic composition and species diversity of weed community after 10 years of different cropping systems and soil tillage in a Mediterranean environment. Weed Research 58, 273-283. https://doi.org/10.1111/wre.12301.

Cicuzza, D., Clough, Y., Tjitrosoedirdjo, S.S., Kessler, M. 2012. Responses of terrestrial herb assemblages to weeding and fertilization in cacao agroforests in Indonesia. Agroforestry Systems 85, 75-83. https://doi.org/10.1007/ s10457-011-9456-6.

Derksen, D.A., Lafond, G.P., Thomas, A.G., John, E.A. 1993. Impact of agronomic practices on weed communities - tillage systems. Weed Science 41, 409-417. https://doi.org/10.1017/S0043174500052127.

Doucet, C., Weaver, S.E., Hamill, A.S., Zhang, J. 1999. Separating the effects of crop rotation from weed management on weed density and diversity. Weed Science 47, 729-735. https://doi.org/10.1017/S0043174500091402.

Farooq, M., Flower, K.C., Jabran, K., Wahid, A., Siddique, K.H.M. 2011. Crop yield and weed management in rainfed conservation agriculture. Soil Tillage and weed management in rainfed conservation agriculture. So
Research 117, 172-183. https://doi.org/10.1016/j.still.2011.10.001.

Ferrara, G., Mazzeo, A., Matarrese, A., et al. 2015. Soil management systems: effects on soil properties and weed flora. South African Journal of Enology and Viticulture 36, 11-20. https://doi.org/10.21548/36-1-932.

Ferreira M.I. 2020. Weed community assessment and response to smother cropping strategies at George, South Africa. Journal of Experimental Biology and Agricultural Sciences 8, 369-380. https://doi.org/10.18006/2020.8(4).36 9.380

Ferreira, M.I., Reinhardt, C.F. 2016. Allelopathic weed suppression in agroecosystems: A review of theories and practices. African Journal of agroecosystems: A review of theories and practices. African Journal of
Agricultural Research 11, 450-459. https://doi.org/10.5897/AJAR2015.10580.

Ferreira, M.I., Reinhardt, C.F. 2010. Field assessment of crop residues for allelopathic effects on both crops and weeds. Agronomy Journal 102, 1593-1600. https:// effects on both crops and weeds. A
doi.org/10.2134/agronj2010.0269.

Fried, G., Kazakou, E., Gaba, S. 2012. Trajectories of weed communities explained by traits associated with species' response to management practices. Agriculture, Ecosystems and Environment 158, 147-155. https://doi.org/10.1016/j. agee.2012.06.005.

Gaba, S., Perronne, R., Fried, G., et al. 2017. Response and effect traits of arable weeds in agro-ecosystems: a review of current knowledge. Weed Research 57, 123-147. https://doi.org/10.1111/wre.12245.

Garcia, R.R., Mifiarro, M. 2014. Role of floral resources in the conservation of pollinator communities in cider-apple orchards. Agriculture, Ecosystems and Environment 183, 118-126. https://doi.org/10.1016/j.agee.2013.10.017.

Garnier, E., Nava, M.L. 2012. A trait-based approach to comparative functional plant ecology: concepts, methods and applications for agroecology. A review. Agronomy for Sustainable Development 32, 365-399. https://doi.org/10.1007/ s13593-011-0036-y.

Gunton, R.M., Petit, S., Gaba, S. 2011. Functional traits relating arable weed communities to crop characteristics. Journal of Vegetation Science 22, 541 550. https://doi.org/10.1111/j.1654-1103.2011.01273.x.
Halde, C., Bamford, K.C., Entz, M.H. 2015. Crop agronomic performance under a six year continuous organic no-till system and other tilled and conventionallymanaged systems in the Northern Great Plains of Canada. Agriculture, Ecosystems \& Environment 213, 121-130. https://doi.org/10.1016/j. agee.2015.07.029.

Haq, S.M., Malik, A.H., Khuroo, A.A., Rashid, I. 2019. Floristic composition and biological spectrum of Keran - a remote valley of northwestern Himalaya. Acta Ecologica Sinica 39, 372-379. https://doi.org/10.1016/j.chnaes.2018.12.001.

Juarez-Escario, A., Conesa, J.A., Solé-Senan, X.O. 2017. Management as a driver of functional patterns and alien species prominence in weed communities of irrigated orchards in Mediterranean areas. Agriculture, Ecosystems \& of irrigated orchards in Mediterranean areas. Agriculture, Ecosystems
Environment 249, 247-255. https://doi.org/10.1016/j.agee.2017.07.042.

Kropff, M.J., Weaver, S.E., Smits, M.A. 1992. Use of eco-physiological models for crop-weed interference: relations amongst weed density relative time of weed emergence, relative leaf area and yield loss. Weed Science 40, 296-301. https://doi.org/10.1017/S0043174500057374.

Mas, M.T., Poggio, S.L., Verdu, A.M.C. 2007. Weed community structure of mandarin orchards under conventional and integrated management in northern Spain. Agriculture, Ecosystems \& Environment 119, 305-310. https:// doi.org/10.1016/j.agee.2006.07.016.

MacLaren, C., Bennett, J. Dehnen-Schmutz, K. 2019. Management practices influence the competitive potential of weed communities and their value to biodiversity in South African vineyards. Weed Research 59, 93-106. https://doi.org/10.1111/wre.12347.

McCully, K.V., Sampson, M.G., Watson, A.K. 1991. Weed survey of Nova Scotia lowbush blueberry (Vaccinium angustifolium) fields. Weed Science 39, 180-185. https://doi.org/10.1017/S0043174500071447.

Milberg, P., Hallgren, E. Palmer, M.W. 2000. Interannual variation in weed biomass on arable land in Sweden. Weed Research 40, 311-321. https://doi. org/10.1046/j.1365-3180.2000.00190.x.

Moeini, M.M., Baghestani, M.A., Mashhadi, H.R. 2008. Introducing an abundance index for assessing weed flora in survey studies. Weed Biology and Management 8, 172-180. https://doi.org/10.1111/j.1445-6664.2008.00293.x.

Nagy, K., Lengyel, A., Kovács, A., et al. 2018. Weed species composition of smallscale farmlands bears a strong crop-related and environmental signature. Weed Research 58, 46-56. https://doi.org/10.1111/wre.12281.

Linares, J., Scholberg, J., Boote, K., et al. 2008. Use of the cover crop weed index to evaluate weed suppression by cover crops in organic citrus orchards. HortScience 43, 27-34. https://doi.org/10.21273/HORTSCI.43.1.27.

Navas, M.L. 2012. Trait-based approaches to unravelling the assembly of weed communities and their impact on agro--ecosystem functioning. Weed Research 52, 479-488. https://doi.org/10.1111/j.1365-3180.2012.00941.x.

Ruisis, P., Frangipane, B., Amato, G. 2015. Weed seedbank size and composition in a long term tillage and crop sequence experiment. Weed Research 55, 320-328. https://doi.org/10.1111/wre.12142.

SAS Institute Inc., 2008. SAS Version 9.2, SAS Institute Inc, SAS Campus Drive, Cary, North Carolina 27513

Shrestha, A., Knezevic, S.Z., Roy, R.C., Ball-Coelho, B.R., Swanton, C.J. 2001. Effect of tillage, cover crop and crop rotation on the composition of weed flora in a sandy soil. Weed Research 42, 76-87. https://doi.org/10.1046/j.13653180.2002.00264.x

Swanepoel, P.A., Du Preez, C.C., Botha, P.R., Snyman, H.A., 2015. A critical view on the soil fertility status of minimum-till kikuyu-ryegrass pastures in South Africa. African Journal of Range \& Forage Science 32, 113-124. https://doi.org $/ 10.2989 / 10220119.2015 .1008043$

Soil Classification Working Group., 1991. Soil classification: a taxonomic system for South Africa. Memoirs on the Agricultural Natural Resources of South Africa no. 15. Pretoria: Department of Agricultural Development.

Soil Survey Staff., 2003. Keys to soil taxonomy. Washington, DC: USA Department of Agriculture.

Ter Braak, C.J.F., Verdonschot, P.F.M. 1995. Canonical correspondence analysis and related multivariate methods in aquatic ecology. Aquatic Sciences 57, 255-289. https://doi.org/10.1007/BF00877430.

Van Acker, R.C., Thomas, A.G., Leeson, J.Y., Knezevic, S.Z., Frick, B.L. 2000. Comparison of weed communities in Manitoba ecoregions and crops. Canadian Journal of Plant Science 80, 963-972. https://doi.org/10.4141/P99-175.

Wedryk, S., Cardina, J. 2012. Smother crop mixtures for Canada thistle (Cirsium arvense) suppression in organic transition. Weed Science 60, 618-623. https:// doi.org/10.1614/WS-D-11-00140.1. 